\title{
Sumber-sumber Dana Bank
}

PRESENTED BY:

ENNY WATI, SE., M.Si

ennywati75@gmail.com 


\section{Sumber-sumber Dana Bank}

Simpanan Giro

Simpanan Tabungan

Simpanan Deposito 


\section{Sumber-sumber Dana Bank}

- Dana yang berasal dari bank itu sendiri

- Setoran modal pemegang saham

- Cadangan-cadangan bank, bagian laba yang tidak dibagi

- Laba bank yang belum dibagi

- Dana yang beradal dari masyarakat luas

- Simpanan giro

- Simpanan tabungan

- Simpanan deposito

- Dana yang berasal dari lembaga lain

- KLBI

- Pinjaman antar bank (call money)

- Pinjaman dari bank luar negeri

- SBPU 


\section{Simpanan Giro (Demand Deposit)}

UU Perbankan No 10/1998 "giro adalah simpanan yang penarikannya dapat dilakukan setiap saat dengan menggunakan cek, bilyet giro, sarana perintah pembayaran lainnya atau dengan cara pemindahbukuan

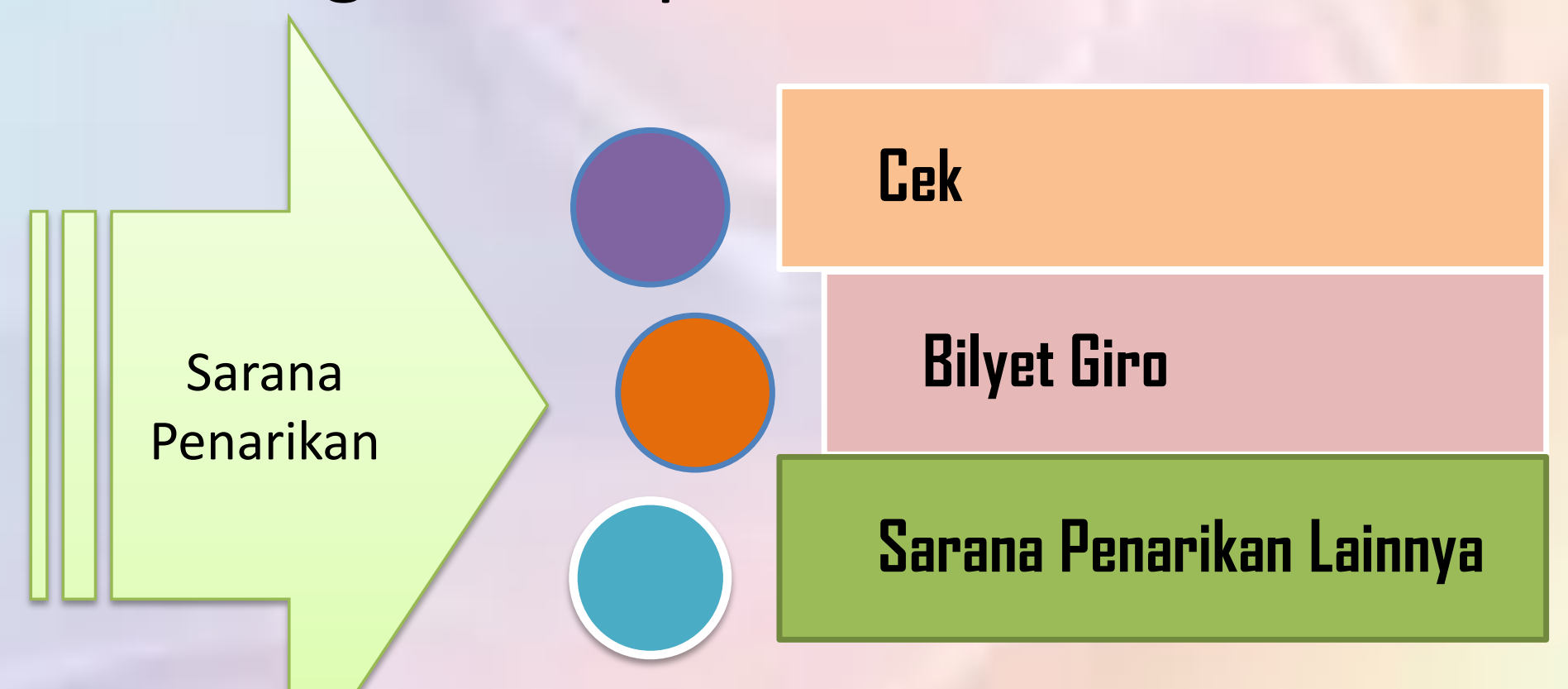




\section{Jenis cek}

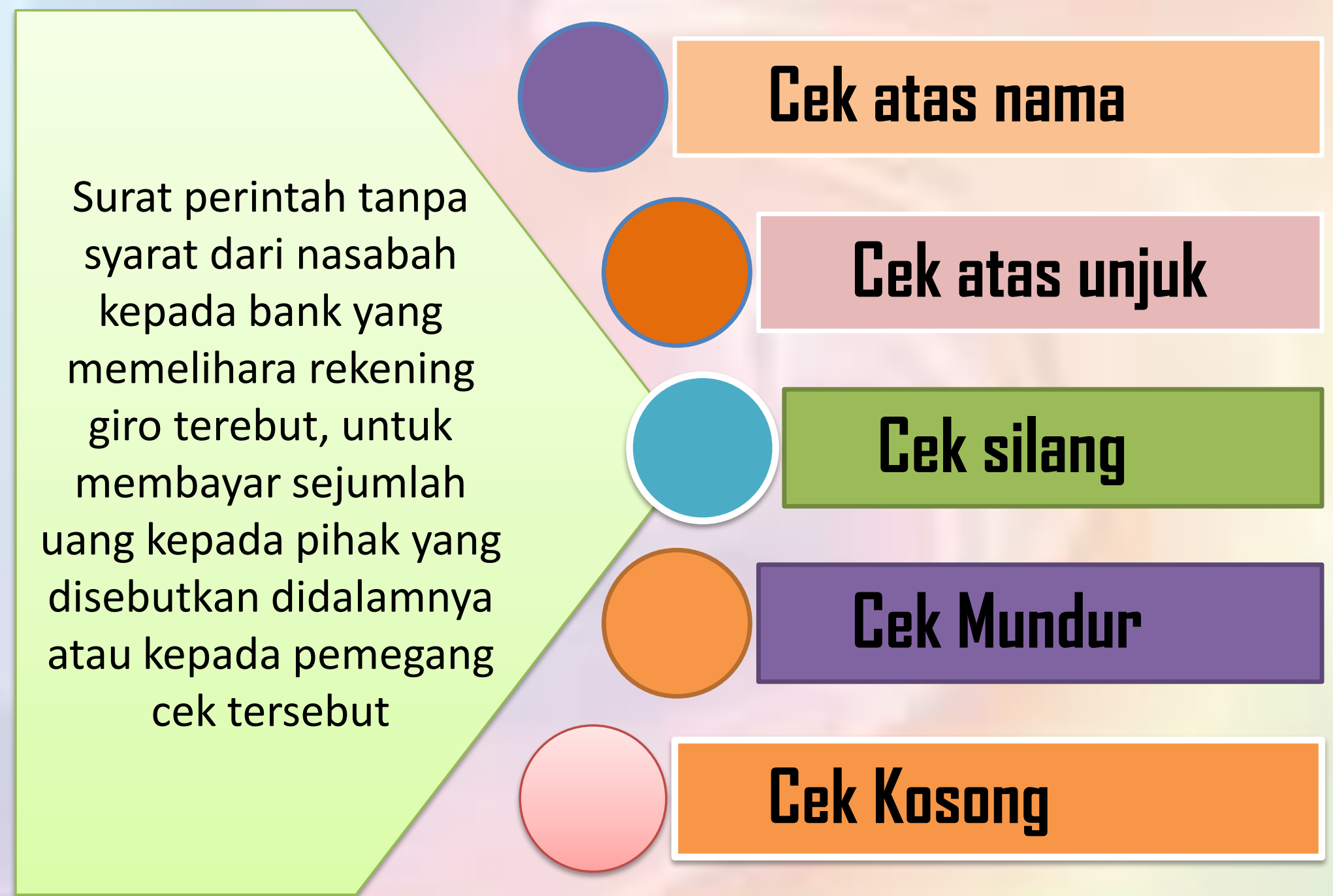




\section{$B G$}

- Surat perintah dari nasabah kepada bank yang memelihara rekening giro nasabah tersebut untuk memindahbukukan sejumlah uang dari rekening yang bersangkutan kepada pihak penerima yang disebutkan namanya pada bank yang sama atau bank lainnya

\section{Alat Pembayaran Lainnya}

- Surat perintah kepada bank yang dibuat secara tertulis pada kertas yang ditandatangani oleh pemegang rekening atau kuasa untuk membayar sejumlah uang tertentu kepada pihak lain pada bank yang sama atau bank lain 


\section{Perbedaan cek dan BG}

\begin{tabular}{|c|l|l|c|}
\hline No & Keterangan & \multicolumn{1}{|c|}{ Cek } & BG \\
\hline 1 & Identitas & $\begin{array}{l}\text { Atas nama dan } \\
\text { atas unjuk }\end{array}$ & Atas nama \\
\hline 2 & Sifat & $\begin{array}{l}\text { Tunai dan Non } \\
\text { tunai }\end{array}$ & Non Tunai \\
\hline 3 & Tanggal & $\begin{array}{l}\text { hanya ada 1 } \\
\text { tanggal }\end{array}$ & $\begin{array}{c}\text { ada dua } \\
\text { tanggal }\end{array}$ \\
\hline
\end{tabular}


Transaksi yang terjadi pada rekening giro Tn. Eko selama Bulan Maret 2019

Nama Nasabah : Tn. Eko

No Rek:

3 Maret setor tunai

8 Maret tarik tunai

13 Maret setor tunai

16 Maret setor kliring

18 Maret tarik tunai

19 Maret setor kliring

24 Maret kliring masuk

27 Maret setor tunai
$18,000,000$

$6,000,000$

$7,000,000$

$1,000,000$

$5,000,000$

$2,000,000$

$7,000,000$

$4,000,000$

Hitung bunga bersih selama bulan Maret jika bunga dihitung dari saldo terendah dan

Saldo rata-rata pada bulan yang bersangkutan dengan suku bunga $18 \%$ pertahun dan pajak $15 \%$ 


\section{Laporan Rekening Koran \\ Tn. Eko}

per 31 Maret 2019

\begin{tabular}{|c|l|c|c|c|}
\hline Tgl & \multicolumn{1}{|c|}{ Transaksi } & Debet & Kredit & Saldo \\
\hline 3 & Setor Tunai & - & 18,000 & 18,000 \\
\hline 8 & Tarik Tunai & 6,000 & - & 12,000 \\
\hline 13 & Setor Tunai & - & 7,000 & 19,000 \\
\hline 16 & Setor Kliring & - & 1,000 & 20,000 \\
\hline 18 & Tarik Tunai & 5,000 & - & 15,000 \\
\hline 19 & Setor Kliring & - & 2,000 & 17,000 \\
\hline 24 & Kliring Masuk & 7,000 & - & 10,000 \\
\hline 27 & Setor Tunai & - & 4,000 & 14,000 \\
\hline
\end{tabular}


1. Perhitungan bunga dengan menggunakan saldo terendah

Saldo Terendah Rp. 10,000,000

Bunga pada bulan Maret 2019

\section{Bunga $=18 \% \times$ Rp. 10.000.000/12 Bulan $=\operatorname{Rp} 150,000$}

Pajak $=15 \% \times \operatorname{Rp} .150 .000=\operatorname{Rp} 22,500$

Bunga Bersih

$=\operatorname{Rp} 127,500$ 
2. Perhitungan bunga dengan menggunakan saldo rata-rata

Saldo rata-rata bulan Maret

\section{$125.000 .000 / 8=15,625,000$}

Bunga pada bulan Maret 2019

Bunga $18 \% \times$ Rp. $15.625 .000 / 12$ bulan $=\operatorname{Rp} 234,375$

Pajak $15 \%$ x Rp. 234.375

$=\operatorname{Rp} 35,156$

Bunga Bersih

$=\operatorname{Rp} 199,219$

Perbedaan Perhitungan :

Bunga dengan Saldo rata-Rata

$=\operatorname{Rp} 234,375$

Bunga dengan Saldo Terendah

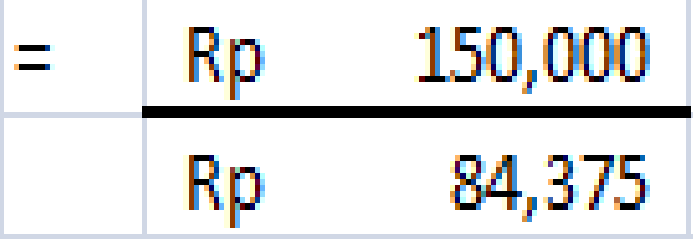




\section{Simpanan Tabungan (Saving Deposit)}

- UU Perbankan No. 10/1998 “Simpanan yang penarikannya hanya dapat dilakukan menurut syarat-syarat tertentu yang disepakati, tetap tidak dapat ditarik dengan cek, bilyet giro dan alat-alat lainnya yang dipersamakan dengan itu

\section{Buku Tabungan}

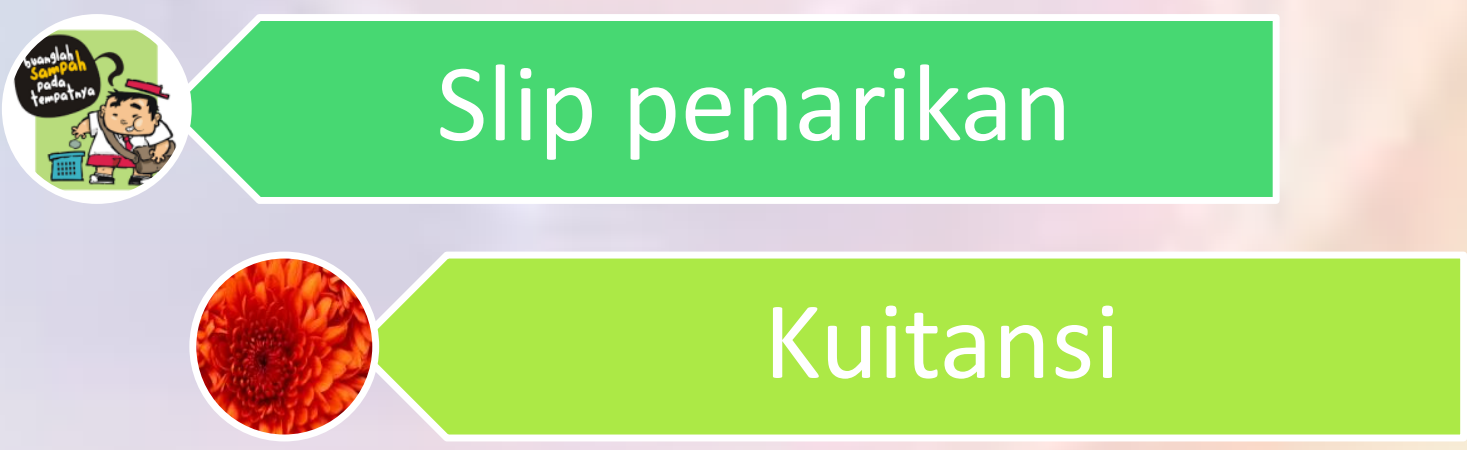

\section{Kartu ATM}


Transaksi yang terjadi di rekening tabungan Tn. Eko selama bulan Maret 2019

1 Maret setor tunai

10 Maret Setor Tunai

12 Maret Tarik tunai

16 Maret Transfer Masuk

20 Maret tarik tunai

30 Maret setor tunai
$6,000,000$

$4,000,000$

$3,000,000$

$2,000,000$

$5,000,000$

$1,000,000$

Pembebanan suku bunga $18 \%$ untuk perhitungan saldo terendah, dan untuk saldo harian dengam suku bunga sebagai berikut :

Dari tanggal $1 \mathrm{~s} / \mathrm{d} 10$ bunga $18 \% /$ tahun

Dari tanggal $11 \mathrm{~s} / \mathrm{d} 20$ bunga $15 \%$ / tahun

Dari tanggal $21 \mathrm{~s} / \mathrm{d} 30$ bunga $20 \%$ / tahun

Hitung bunga bersih Tn. Eko dengan menggunakan saldo terendah dan saldo harian jika dikenakan pajak $15 \%$ 


\section{Laporan Rekening Tabungan \\ Tn. Eko}

per 31 Maret 2019

\begin{tabular}{|c|l|c|c|c|}
\hline Tgl & \multicolumn{1}{|c|}{ Transaksi } & Debet & Kredit & \multicolumn{1}{c|}{ Saldo } \\
\hline 1 & Setor Tunai & - & 6,000 & 6,000 \\
\hline 10 & Setor Tunai & - & 4,000 & 10,000 \\
\hline 12 & Tarik Tunai & 3,000 & - & 7,000 \\
\hline 16 & transfer masuk & - & 2,000 & 9,000 \\
\hline 20 & Tarik Tunai & 5,000 & - & 4,000 \\
\hline 30 & Setor Tunai & - & 1,000 & 5,000 \\
\hline
\end{tabular}




\section{Perhitungan bunga dengan saldo terendah}

Saldo terendah $\mathrm{Rp}, 4,000,000$

\section{Bunga $=18 \% \times R p, 4,000=\operatorname{Rp} 60,000$}

Pajak 15\% x Rp, 60,000 $=$ Rp 9,000

Bunga Bersih $=\operatorname{Rp~51,000}$ 
2. Perhitungan bunga dengan saldo harian

Tanggal 1 sid 9 Haret

Bunga = 16\% н Fip. 6.000.0001365 $\times$ 9 Hari $=$ Pip 26.630

Tanggal 10 Haret

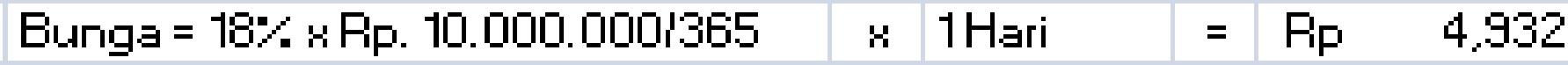

Tanggal 11 Haret

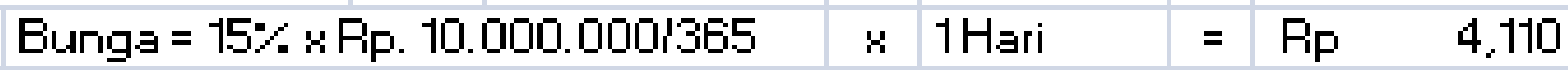

Tanggal 12 sid 15 Maret

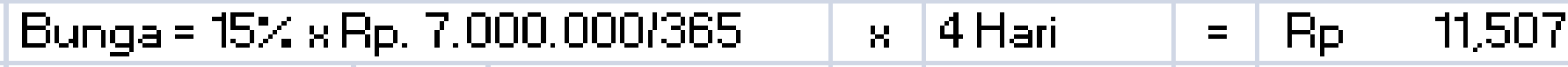

Tanggal 16 s.ld 19 Haret

Bunga= $15 \%$ \& Rip. 9.000.0001.365 $\quad$ в 4 Hari $=$ Fip 14.795

Tanggal 20 Haret

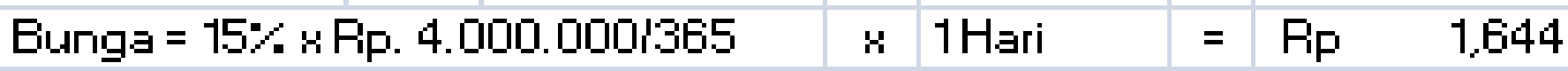

Tanggal 21 sid 29 Haret

Bunga = 20\% н Pip. 4.000.0001365 $\times 9 \mathrm{Hari}=$ Pif 19.726

Tanggal 30 Haret

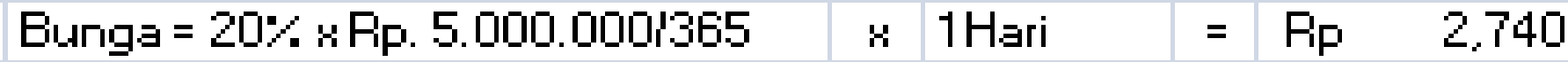

Total bunga harian $=$ Fip 86,084

Pajak 15\% r Rp. 86.0t $=$ Pip 12.913

Bunga Bersih

$=$ Fif 73.171 


\section{Simpanan Deposito (Time Deposit)}

- UU Perbankan No.10/1998 "simpanan yang penarikannya hanya dapat dilakukan pada waktu tertentu berdasarkan perjanjian nasabah penyimpan dengan bank

\section{Deposito Berjangka}

\section{Sertifikat deposito}

Depusito on call 
- Deposito Berjangka

- Deposito yang diterbitkan menurut jangka waktu tertentu $(1,2,3,6,12,18 \mathrm{sd} 24$ bulan) atas nama dan atas unjuk

- Sertifikat deposito

- deposito yang diterbitkan dengan jangka waktu 2,3,6,12 dan 24 bulan, atas unjuk dan dapat dipindahtangankan atau diperjualbelikan

- Deposito on call

- deposito yang berjangka minimal 7 hari dan paling lama kurang dari 1 bulan. Diterbitkan atas nama dan biasanya dalam jumlah besar 


\section{Perhitungan Deposito berjangka}

- Tn X ingin menerbitkan deposito berjangka untuk waktu 6 bulan nominal Rp. 40.000 .000 bunga 18\% PA (pertahun) bunga diambil setiap bulan tunai. Saat jatuh tempo deposito dicairkan dan diambil tunai

- Berapa jumlah bunga yang diterima Tn X setiap bulan jika dikenakan pajak 15\%

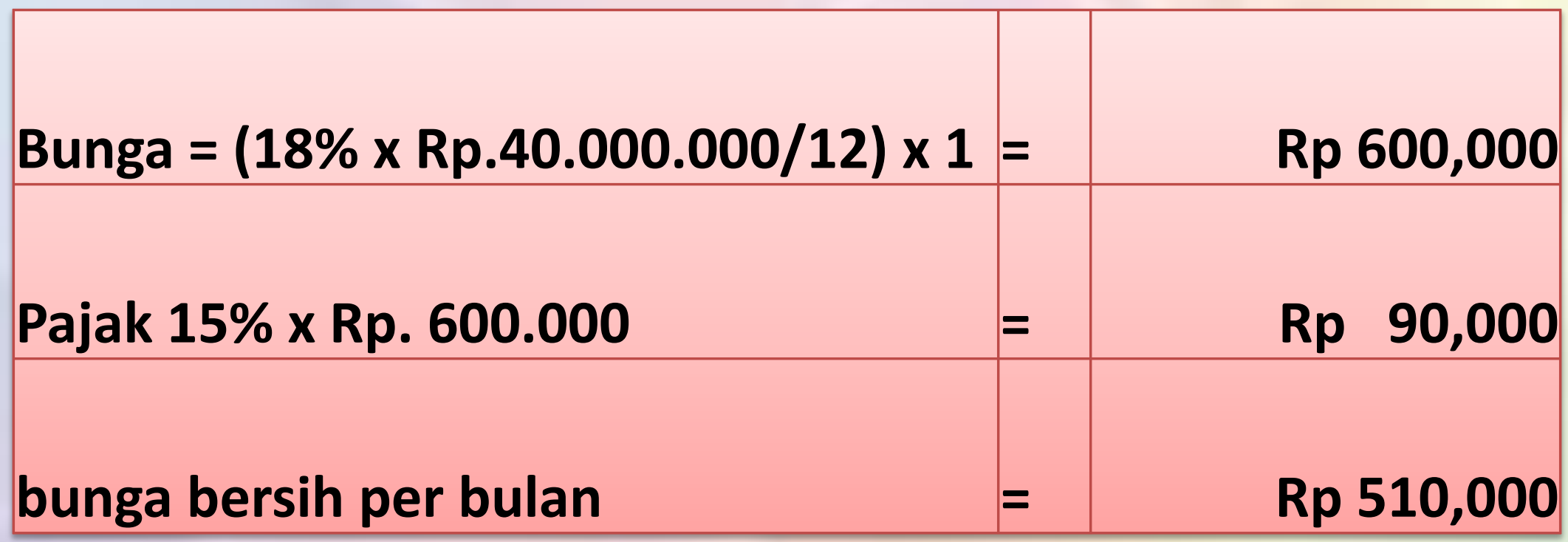


- Dik. Deposito berjangka nominal Rp.10.000.000, jangka waktu 9 bulan, bunga 18\% PA dan diambil setelah jatuh tempo

- Berapa jumlah bunga yang diterima jika dikenakan pajak $15 \%$

Bunga $=(18 \% \times$ Rp. $10.000 .000 / 12) \times 9=R p 1,350,000$

Pajak 15\% x Rp. 600.000

$=\operatorname{Rp} 202,500$

bunga bersih per bulan

$=\quad R p 1,147,500$ 


\section{Perhitungan Bunga Sertifikat Deposit0}

- Tn Z membeli 10 Lembar sertifikat deposito nominal @ Rp. 10.000.000, bunga 14\% PA dan diambil dimuka. Jangka waktu 12 bulan dan pembayaran secara tunai

- Berapa jumlah yang harus Tn Z bayar kepada pihak bank jika dikenakan pajak $15 \%$

\begin{tabular}{|c|c|c|c|}
\hline $\begin{array}{l}\text { Total sertifikat deposito } 10 \times \text { Rp. Rp. } \\
10.000 .000\end{array}$ & $=$ & $\mathbf{R p}$ & $\lfloor 00,000,000$ \\
\hline Bunga $=(14 \% \times$ Rp. $100.000 .000 / 12) \times 12$ & $=$ & $\mathbf{R p}$ & $14,000,000$ \\
\hline \multirow[t]{2}{*}{ Pajak 15\% x Rp. 14.000 .000} & $=$ & Rp & $2,100,000$ \\
\hline & & $\mathbf{R p}$ & $11,900,000$ \\
\hline Jumlah yang harus dibayar & & Rp & $88,100,000$ \\
\hline
\end{tabular}


- Ny. A membeli 5 lembar sertifikat deposito nominal @ 2.000.000, jangka waktu 3 bulan. Pembayaran dibebankan ke rekning tabungan. Bunga $17 \%$ dan diambil dimuka tunai

- Berapa jumlah bunga yang diterima jika dikenakan pajak $15 \%$ dan diambil dimuka tunai

Total sertifikat deposito 5 x Rp. 2.000 .000

Bunga $=(17 \% \times$ Rp. $10.000 .000 / 12) \times 3$

Pajak 15\% x Rp. 425.000
$=\operatorname{Rp} 10,000,000$

$=R p \quad 425,000$

$=\quad \mathbf{R p} \quad 63,750$

$\mathbf{R p}$

361,250 


\section{Perhitungan Deposito On Call}

- Tn A ingin memerbikan deposito on call mulai 3 Maret 2019, bunga yang dinegoisasi 3\% PM, diambil pada saat pencairan.

- Tanggal 18 Maret 2019 Tn. A mencairkan deposito on callnya

- Berapa jumlah bunga yang diterima pada saat pencairan jk dikenakan pajak $15 \%$

Bunga $=(3 \% \times \operatorname{Rp} .200 .000 .000 / 30) \times 16=\operatorname{Rp} 3,200,000$

Pajak 15\% x Rp. 3.200 .000

$\begin{array}{rrr}= & \operatorname{Rp} & 480,000 \\ & \operatorname{Rp} & 2,720,000\end{array}$




\section{Jika Ditarik Sebelum Jatuh Tempo}

- 16 Maret 2019 Tn X menerbitkan sertifikat deposito berjangka senilai Rp. 10.000.000, jangka waktu 3 bulan, pembayaran dibebankan ke rekening tabungan, bunga $12 \%$ PA diambil setiap bulan tunai

- Karena suatu hal, Tn X mencairkan depositonya pada tanggal 14 Mei 2019. untuk hal itu dikenakan Finalty Rate sebesar 3\% dan pajak $15 \%$

- Berapa denda yang harus dibayar oleh Tn. X

$16 / 3$ $16 / 4$ $16 / 5$ $16 / 6$

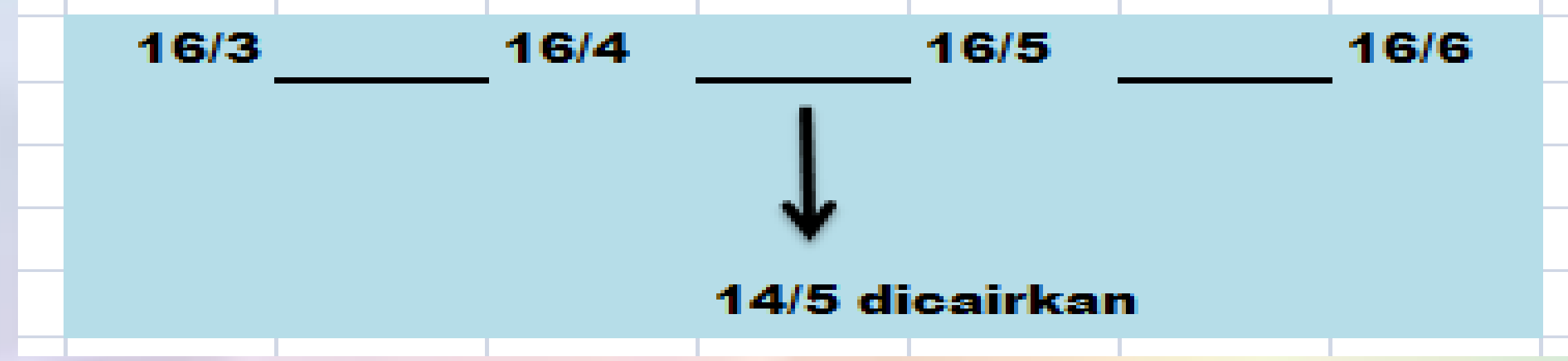




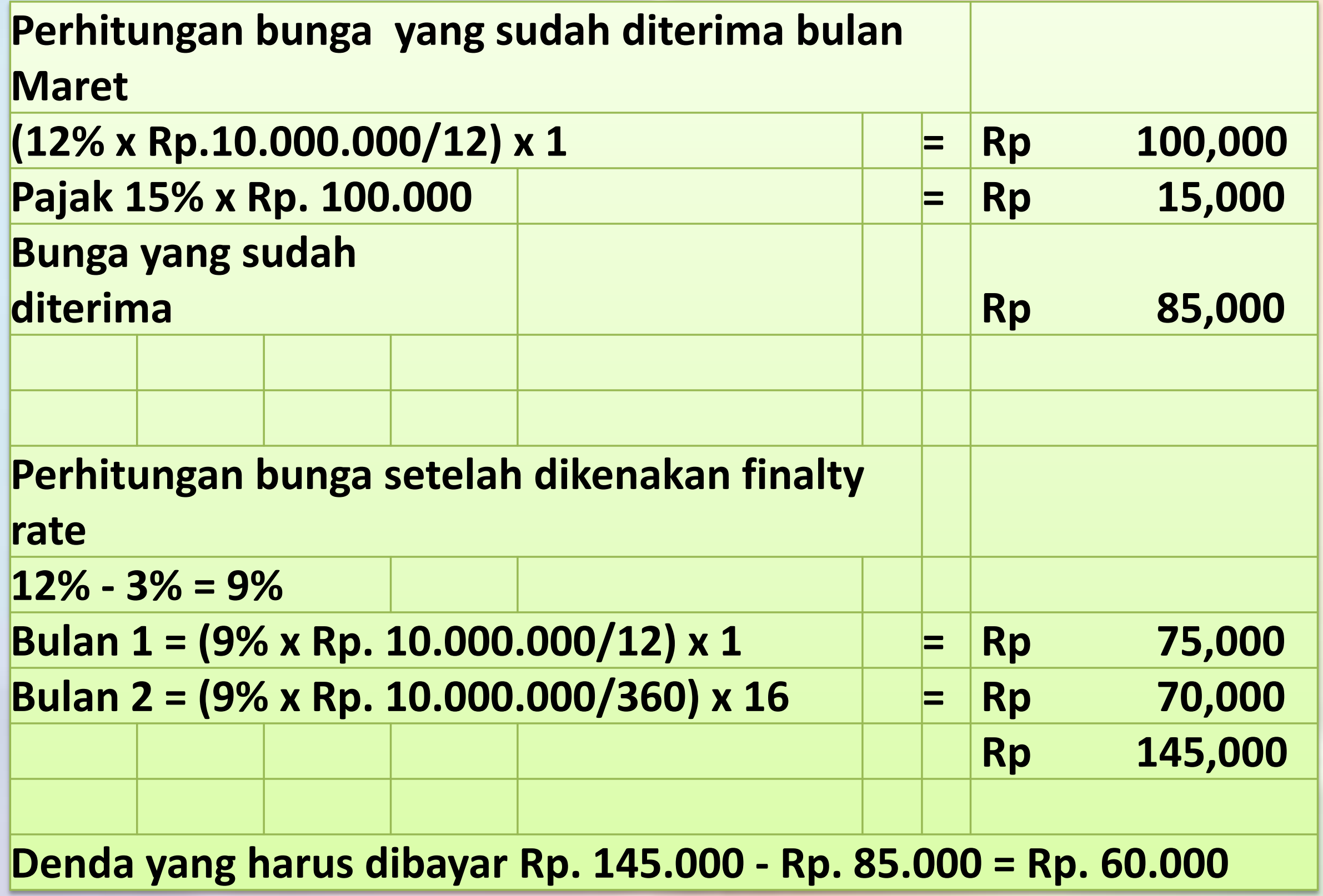


- Sumber :

Dr. Kasmir, SE.,MM, Bank dan Lembaga keuangan lainnya, Edisi revisi ke-8, Penerbit Raja Grasindo Persada, Jakarta.2008. 


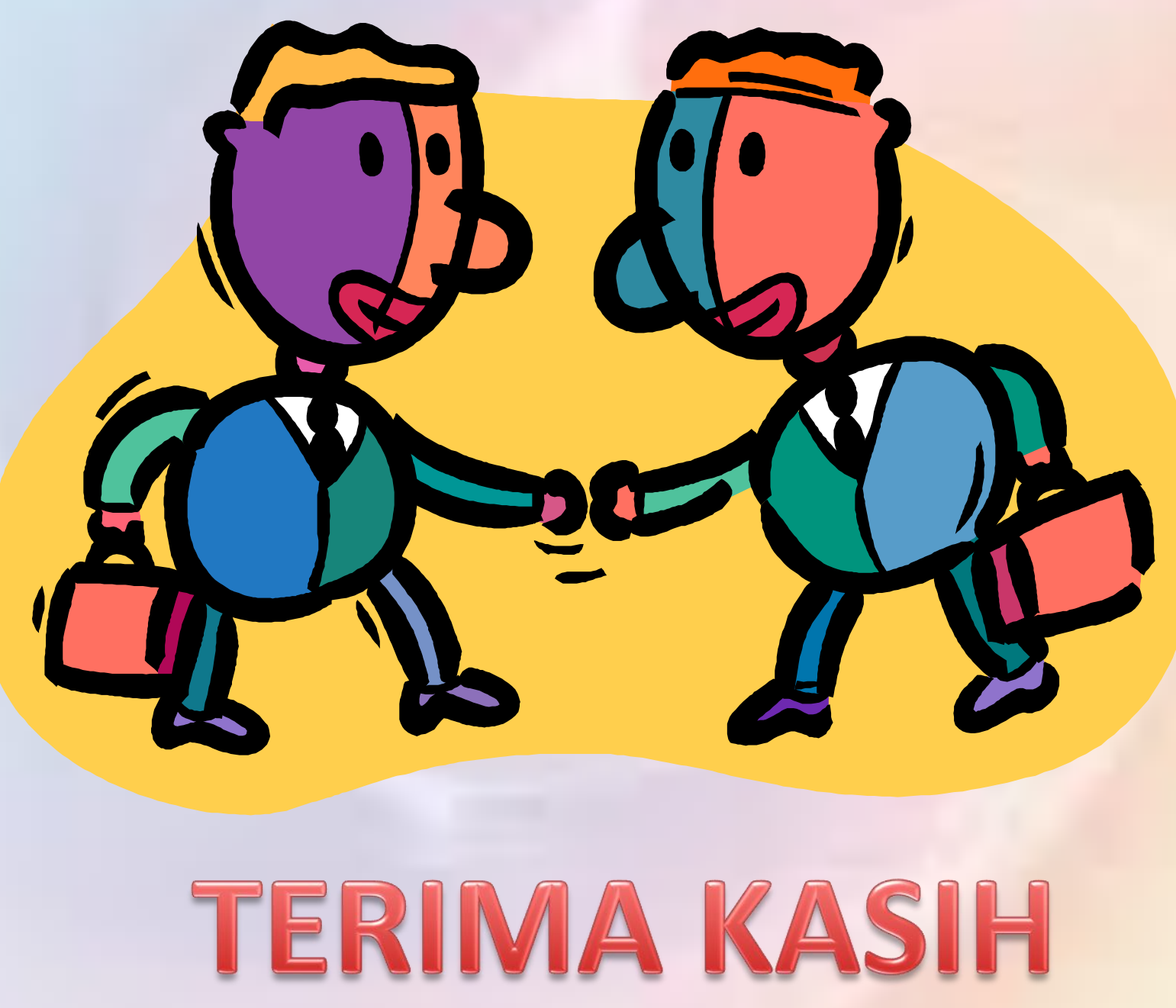

